\title{
URBAN LAYOUT FOR BUILDING SOLAR OPTIMIZATION AND OUTDOOR COMFORT BALANCE: NEIGHBORHOOD STRATEGY IN MEDITERRANEAN CLIMATE
}

\author{
Julia Díaz-Borrego*, Ignacio Acosta, Miguel Ángel Campano, and Samuel Domínguez-Amarillo \\ Department of Building Construction, Universidad de Sevilla, Seville, Spain
}

\begin{abstract}
The urban configuration in the Mediterranean area, which has noticeable solar radiation and significant thermal oscillation, is one of the factors that affect the microclimate and the urban heat island phenomenon of the cities located in that zone. To contribute to the improvement of urban comfort, this work presents an experimental methodological proposal for the analysis and multicriteria optimization of performance indicators using a parametric workflow through Grasshopper. This workflow can lead to the development of a set of environmental design criteria as support tools in the design of the urban configuration. The methodology is based on the quantification of two parameters on the analysis and management of daylight in interior spaces by means of dynamic metrics and, on the other hand, on the evaluation of hygrothermal conditions and the urban heat island effect, which affect both the daytime comfort of passersby and the nighttime comfort of dwellings. This study considers the most typical variables of urban layout, both morphological and material. The case study analyzed is located in the city of Seville (Spain), which has a significant percentage of its contemporary buildings without a suitable adaptation to local climate conditions. The results obtained from the case study prove the potential of the proposed methodology to evaluate and optimize lighting and thermal performance at the neighbourhood scale. Thus, it provides urban planners with a powerful decision support tool for both urban expansion and urban renewal.
\end{abstract}

Keywords: Thermal Comfort; Daylighting; Urban Configuration; Multi-criteria Analysis and Optimization; Urban Heal Island; Outdoor Microclimate.

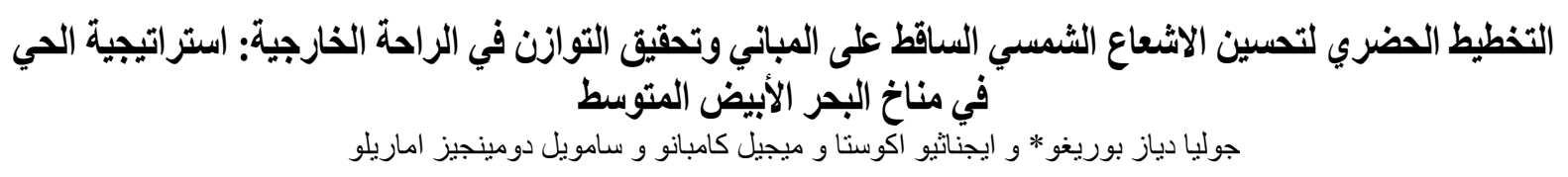

الملخص: يعد التكوين الحضري في منطقة البحر الأبيض المتوسط ـالمعروف بإثنعاع شمسي ملحوظ وتذبذب حراري

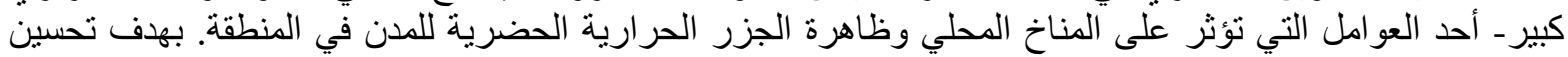

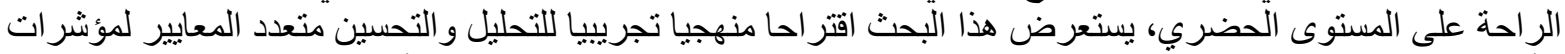

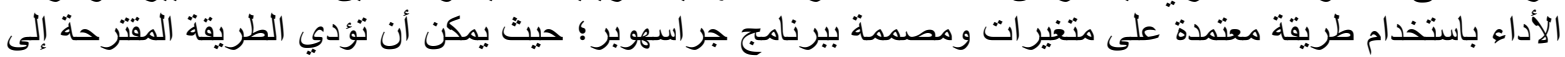

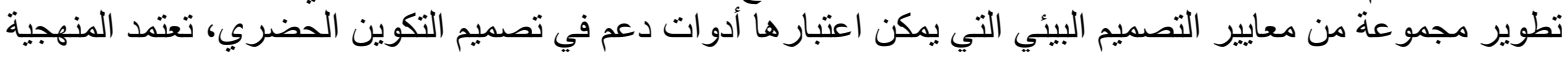

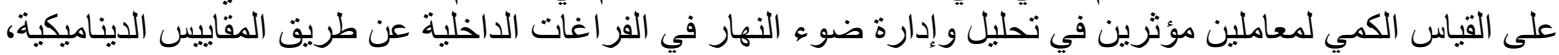

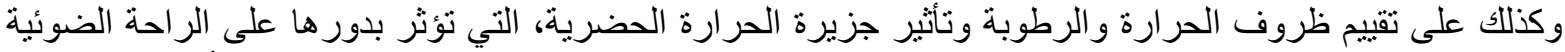

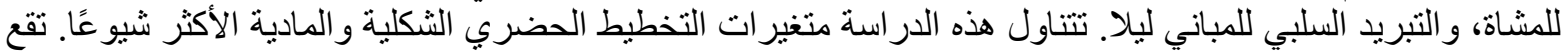

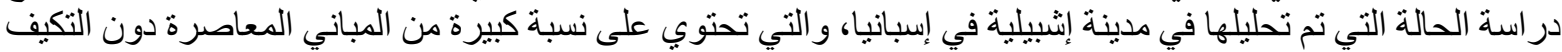

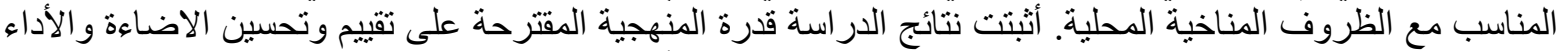

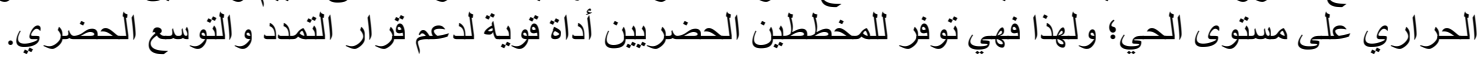

الكلمث المفتاحية: التكوين الحضري؛ جزر حرارية؛ الراحة الحرارية؛ البناء السكني.

*Corresponding author's e-mail: jdiazborrego@us.es 


\section{INTRODUCTION}

Energy efficiency in buildings is nowadays a must. However, a deeper understanding of the urban environment impact on building performance and on the inhabitants' well-being is required.

Solar obstruction caused by the urban environment is the main physical factor affecting lighting comfort (Xue et al., 2014), as well as the proper chrono regulation due to the lack of daylight access. In addition, urban form influences the building energy performance, with an increase of up to $10 \%$ of the energy consumption (Ratti et al., 2005). The urban configuration also affects the climatic and microclimatic variables, playing a decisive role in the urban heat island (UHI) phenomenon, which is mainly responsible for the nocturnal heat stress. Likewise, outdoor temperature, wind speed, and solar radiation to which a building is exposed are not those represented by the synoptic regional climate, but the local microclimate modified by the structure of the city (Givoni, 1989). Thus, the urban configuration determines the outdoor environment quality, modifying the regional climate and affecting the comfort and health of the inhabitants.

Therefore, the correlation of multidisciplinary analyses can act as an active tool in decision-making (Naboni et al., 2019). For this purpose, urban elements that influence the building performance -urban climate, urban morphology and density, and building formmust be integrated with a single calculation. In addition, to assess the environmental efficiency of urban design, it is necessary to perform a comparison between solar accessibility inside buildings and outdoor thermal comfort, which will be affected by the solar potential and the UHI effect, respectively, determining the energy performance of buildings. However, due to its complexity, the coupling of simulation engines for multivariate analysis of urban environmental behaviour has been explored by a few studies (Naboni et al., 2019; Natanian \& Auer, 2020).

\subsection{Background}

Urban environment performance is an essential factor to take into account in building efficiency and comfort analysis; as it influences user thermal sensation (outdoor thermal comfort), as well as the solar accessibility, lighting, and energy consumption of buildings. Therefore, public space configuration affects both the external microclimate and the interior of the building (Ali-Toudert \& Mayer, 2006).

Daylight access is essential to avoid excessive energy consumption and improve visual comfort, as well as to help improve the health of the occupant through proper circadian stimulation (Acosta et al., 2016). Furthermore, circadian disturbance caused by lack of access to natural light can promote depression and other serious medical conditions (Bellia et al., 2020). Thus, compared to electric light, daylight offers better visual comfort by constantly varying its intensity, direction, and spectral composition (Wong, 2017). However, excessive radiation and exposure to daylight can also lead to glare, as well as an excess of solar radiation can lead to overheating and thus a further increase in cooling energy consumption. Therefore, it is necessary to perform an analysis to improve urban layout optimizing the use of daylight, both in terms of thermal radiation management and illuminance.

In this regard, only a small number of studies analyze indoor daylight behaviour using dynamic metrics. Most of them focused on the analysis of opening or shading devices. In addition, most research analyzing urban morphological parameters focuses only on the analysis of the building envelope solar potential.

For its part, the urban configuration also affects the climatic and microclimatic variables, playing a decisive role in the so-called UHI phenomenon. UHI is an effect related to urbanization that causes significant climatic changes. It affects both air temperature and relative humidity, as well as airflow and wind speed in the built environment (Núñez Peiró et al., 2017), raising air temperature values in urban areas compared to rural areas (Street et al., 2013). This phenomenon was first studied by Oke (Oke, 1988) at the end of the nineteenth century, who analyzed its links with different urban morphological parameters. Urban densification contributes to the intensity of UHI, thus affecting the microclimatic conditions of the environment and, consequently, the indoor and outdoor conditions of comfort. It also aggravates the effects of climate change and heatwaves, posing a serious threat to the health and comfort of citizens. Therefore, the UHI is the most appropriate indicator to quantify the environmental modification produced by the effect of urbanization on a specific territory.

Concerning the evaluation parameters, the main parameter that allows evaluating the urban morphology influence on microclimate and daylight accessibility is the urban canyon proportion. This urban parameter, coined by Oke, specifies the ratio between the height of the building and the width of the road $(\mathrm{H} / \mathrm{W})$. Thus, orientation and urban canyon proportion influence solar access potential, airflow, and other microclimatic data, such as the urban heat island effect.

Nowadays, the swift computational tools evolution and development allows more complex analysis by reducing the computational cost. In this sense, several studies have explored the correlation between urban form and different environmental performance parameters; however, few have developed a multicriteria combination of contradictory or conflicting aspects, a complex but essential challenge.

\subsection{Aims and objectives}

This research aims to reach a methodological proposal that allows determining the optimal urban layout to optimize the use of daylight in the Mediterranean area, both in terms of thermal radiation management and illuminance. 
In addition, the proposed methodology also aims to provide a useful evaluation tool for urban planners, allowing predicting with a single workflow both the daylight and the thermal behaviour of the designed urban configuration.

\section{METHODOLOGY}

To promote energy savings and wellness in buildings, it is essential to quantify the urban configuration influence both on the interior daylight access and on the outdoor hygrothermal conditions. However, due to the complex calculations required, there is a lack of these studies. Nevertheless, today, parametric tools development allows the environmental analysis at the urban scale to search for more efficient configurations.

The parametric design method could be defined as a fast way to generate multiple design solutions and configurations by varying the values of the input parameters of the initial design model (Taleb \& Musleh, 2015). Thus, the integration in a parametric and dynamic workflow of urban data sets and the different tools used allows carrying out a multicriteria analysis and optimization.

Therefore, the method proposed in this study brings the integration of several parameters, factors, and metrics in a single parametric workflow through the Rhinoceros 3D software tool with the aid of the Grasshopper application. Grasshopper is a visual programming language that allows the assessment of complex urban systems through a parametric workflow. Such workflow can perform a multi-objective analysis and an optimization process because of the coupling of the simulation engines. The following specific light and environmental simulation programs are used in this workflow: Radiance, EnergyPlus, OpenStudio and Urban Weather Generator (UWG). All of them couple to Grasshopper through Ladybug Tools -Ladybug, Honeybee and Dragonfly-, which acts as a parametric environmental plugin for Grasshopper by means of a free and open-source development (Roudsari \& Pak, 2013).

Thus, this workflow allows a multicriteria analysis and optimization of the initial results, to enhance the lighting efficiency of buildings in an urban fabric, as well as to establish design guidelines for cities for the study of climatic and morphological conditions at the neighbourhood scale.

Figure 1 shows the digital workflow developed for this study, as well as the input data, lighting and thermal metrics and plugins that materialize it. The following sections show the methods used to build this workflow.

\subsection{Input Parameters}

The simulation parameters combine both static and dynamic parameters. Static parameters are those that establish the climatic conditions and define the morphological parameters that are intrinsic to the urban fabric to be analyzed. Dynamic parameters are those that determine the purpose of the evaluation, being related to light optimization and thermal comfort. Thus, these values will vary to quantify their impact.

The geometric model has been performed using Rhinoceros 3D based on the morphological parameters that define the urban fabric to be analyzed. Once the urban geometry has been obtained, it will be parameterized using Grasshopper for its subsequent analysis and optimization.

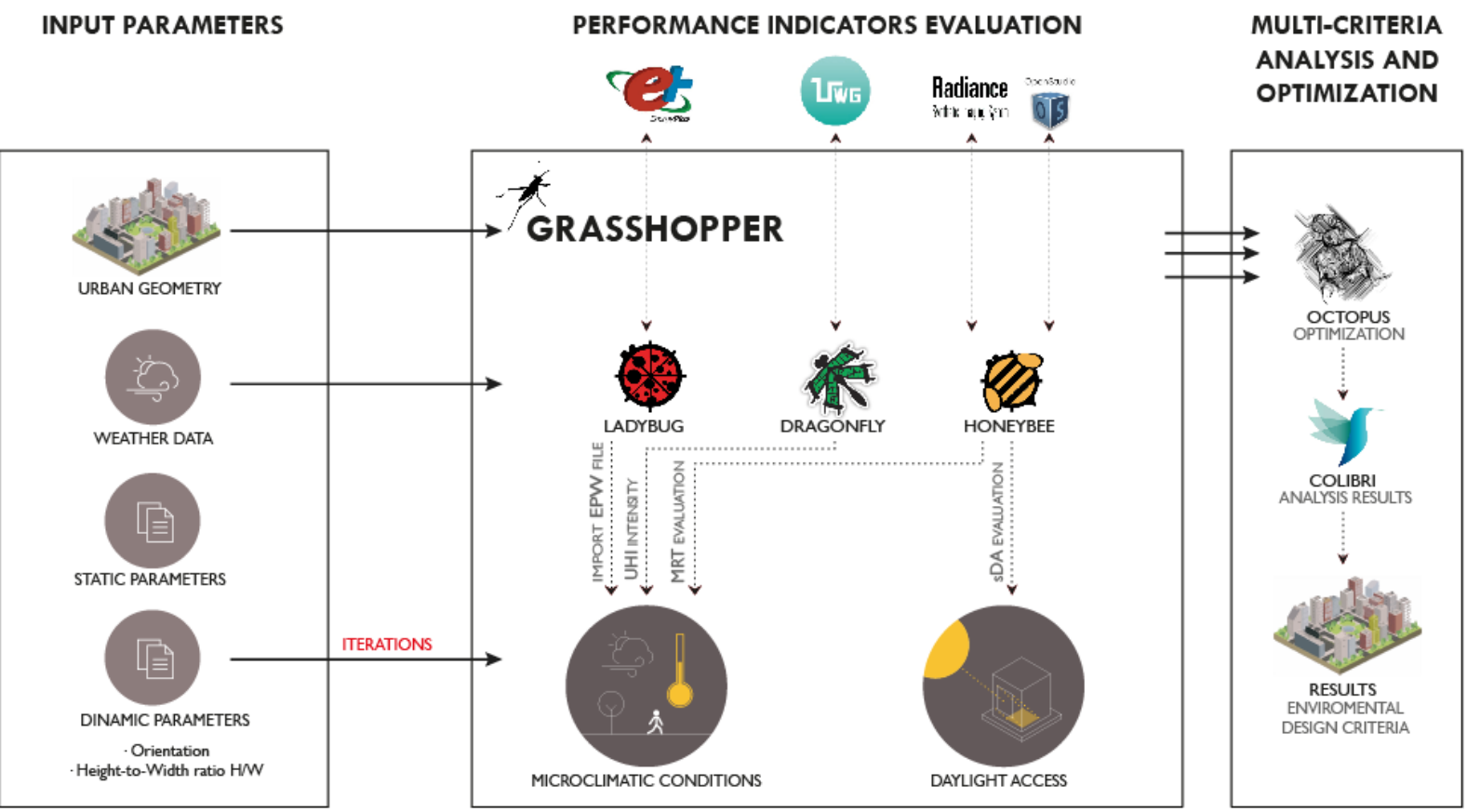

Figure 1. Methodological diagram of the multi-criteria environmental analysis of the parametric workflow in Grasshopper. 
The building understudy has been modelled in greater detail, introducing its floor plans, as well as the facade openings. However, the urban environment has been developed volumetrically, in a much more simplified way since the "influence of volumetric and relative building layout largely overweigh the importance or relevance of geometric detailing on building envelopes" (Compagnon, 2004).

In turn, the weather data file from the location under study was imported in EnergyPlus (*.epw) format. Both direct normal and diffuse horizontal irradiance, as well as the sky model built up by Perez et al. (Perez et al., 1993) and validated by CIE (l'Eclairage, 2003), were used.

\subsection{Microclimatic evaluation method}

$\mathrm{UHI}$ is the most evident and quantitative indicator of the environmental change produced by the effect of urbanization on a specific territory. Its clearest consequence is the increase in air temperature during the night concerning the surrounding rural environment. The UHI intensity is defined as the thermal difference between the urban sector to be analyzed and the nearby rural or non-urban area at a given time (Observatori Metropolità del Canvi Climàtic, 2015). Formally,

$\Delta T_{u-r}=T_{u}-T_{r}$

where $\Delta T_{u-r}$ is the UHI intensity, $T_{u}$ the temperature of the urban area, and $T_{r}$ the temperature of the rural or non-urban area. For this equality to be satisfied, the geographical conditions of both points must be similar. This expression is based on Lowry's additive model (Lowry, 1977) whose simplified expression states:

- The average temperature of a point in the urban area, $T_{u}$, is equal to the sum of the regional climate, $\mathrm{C}$, the effect of local geographic factors in the urban area, $G_{u}$, and the influence of urbanization, $\mathrm{U}$;

$$
T_{u}=C+G_{u}+U
$$

- The average temperature of a point in the rural area, $T_{r}$, is equal to the sum of the regional climate, $\mathrm{C}$, plus the effect of local geographic factors in the rural area., $G_{r}$ :

$$
T_{r}=C+G_{r}
$$

Thus, it is necessary to evaluate the hygrothermal and microclimatic conditions of the urban context correctly to reduce their environmental impact (Salvati et al., 2016). Until now, this analysis has generally been carried out using typical climate samples based on historical records from the nearest meteorological station, which is usually rural; therefore, they were performed without taking into account the effect produced on the climate by the urban environment. Thus, the present study starts with a limitation in the collection of the specific climatological data of the urban context; that prevents an adequate prediction of environmental optimization (Alexander et al., 2015; Nakano et al., 2015). Recent studies have focused on how the urban environment affects climatology (Bueno et al., 2015; Salvati et al., 2016, 2019; Street et al., 2013), as well as the effect of urban microclimate on building performance, resulting in the creation of the Urban Weather Generator (UWG) software. UWG produces a modified weather file, generated from the rural environment file, which reflects the real microclimatic conditions of the urban setting under study. Therefore, the "urban weather conditions" are introduced in the workflow of this study using UWG (through Ladybug and Dragonfly plugins). In this way, Ladybug imports the EnergyPlus weather files (*.epw) -rural weather data- into Grasshopper. For its part, the Dragonfly plugin allows UWG software coupling, which transforms the rural weather data, generating a modified weather file as shown in Figure 2. Finally, the Ladybug plugin performed the detailed analysis of climate data, once transformed into 'urban weather data' and its subsequent visualization, as well as the interaction of said processed data with other plugins.

Once the modified urban weather file is obtained, the real urban thermal radiation is analysed by evaluating the Mean Radiant Temperature (MRT) in the outdoor environment in July, the warmest month of the year. MRT is defined as "the uniform temperature of an imaginary enclosure in which the radiant heat transfer from the human body equals the radiant heat transfer in the actual nonuniform enclosure" (Fundamentals, 2001). The evaluation was carried out using Ladybug Tools, by means of the tools and components shown in Figures 3 and 4, on the outside, to assess which urban configuration is more favourable in this sense.

\subsection{Daylight Evaluation Method}

Daylight potential is quantified using the metric, both spatial and dynamic, spatial Daylight Autonomy (sDA). This one was introduced by the Illuminating Engineering Society of North American (IESNA) in 2012 in the LM-83 lighting protocol for the evaluation of lighting behaviour in architectural spaces (Committee, 2012). The sDA metric indicates daylight sufficiency, defined as the percentage of a surface area that exceeds 300 lux of illuminance during $50 \%$ of the occupancy time.

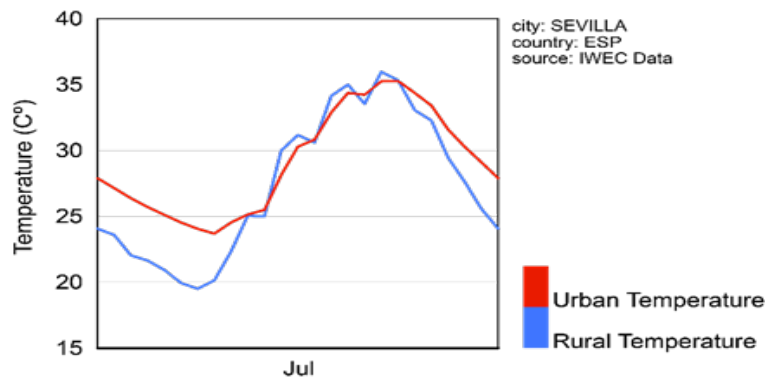

Figure 2. Comparison of the rural and the simulated urban weather. 


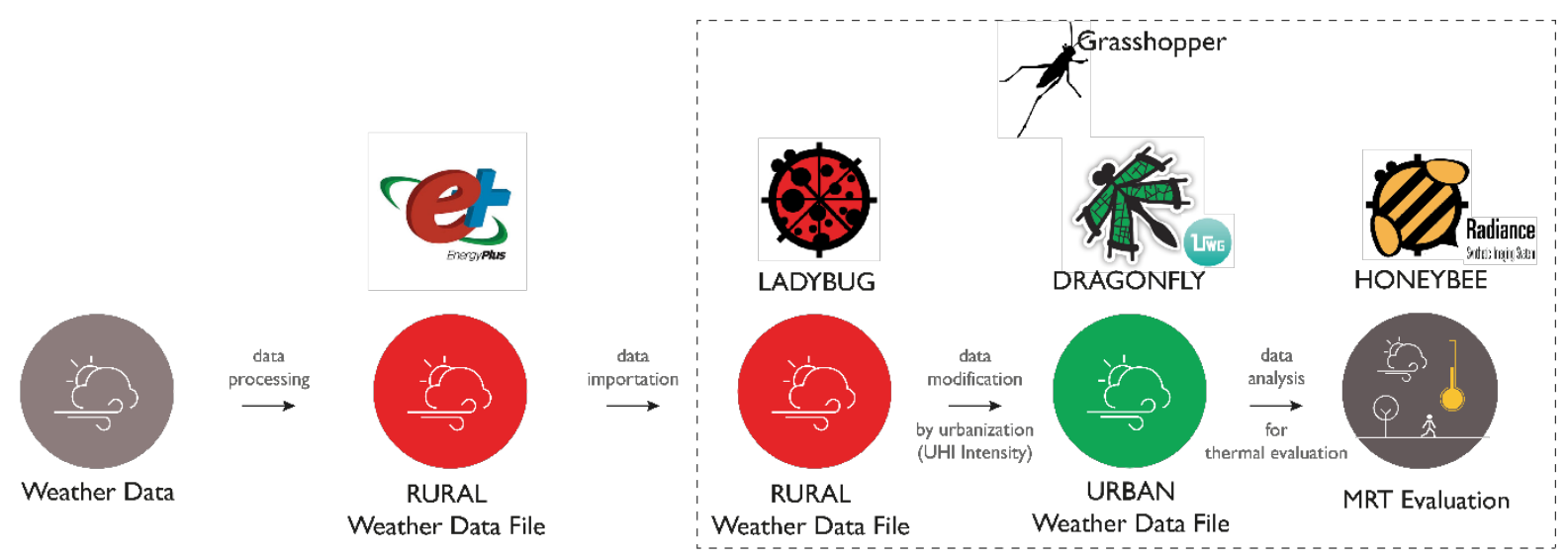

Figure 3. Evaluation workflow to analyze the urban thermal radiation through Ladybug Tools.

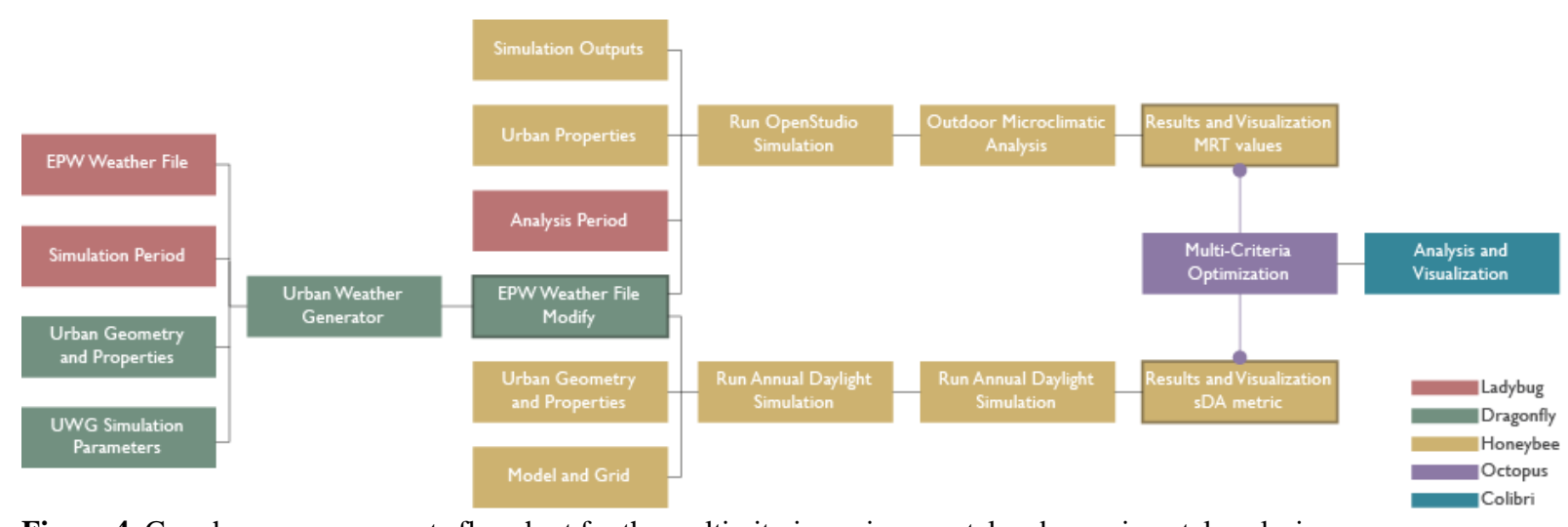

Figure 4. Grasshopper components flowchart for the multicriteria environmental and experimental analysis.

Table 1. Illuminance thresholds and definition of the sDA metric.

\begin{tabular}{cccccc}
\hline Metric & $\begin{array}{c}\text { Minimum } \\
\text { illuminance } \\
\text { threshold }\end{array}$ & $\begin{array}{c}\text { Minimum } \\
\text { temporal } \\
\text { threshold }\end{array}$ & Analysis result & $\begin{array}{c}\text { Acceptable } \\
\text { threshold }\end{array}$ & $\begin{array}{c}\text { Preferred } \\
\text { threshold }\end{array}$ \\
\hline \multirow{2}{*}{ sDA } & 300 lux & $50 \%$ & $\begin{array}{c}\% \text { surface with } \\
\text { sufficient illumination }\end{array}$ & $\begin{array}{c}>55 \% \\
\text { of surface area }\end{array}$ & $\begin{array}{c}>75 \% \\
\text { of surface area }\end{array}$ \\
\hline
\end{tabular}

The illuminance thresholds for the definition of this metric correspond to those stipulated by IESNA (IES LM-83-12) (Table 1). The adopted occupancy time for daylight evaluation is between 8:00-18:00 every day throughout the year, as also recommended by IESNA.

Since the research is based on the comparative analysis of light behaviour resulting from the different variations of the urban fabric, the solar accessibility analysis was carried out without considering blinds. Likewise, other important parameters to be considered, such as the material's reflectance of the urban context or glazing ratios, have been considered as fixed values and, therefore, they were not of relevance in the comparative analysis. This is acceptable as this paper, as mentioned above, focuses on the impact of the urban environment on indoor daylighting quality.

The evaluation was carried out using the plugin of Ladybug Tools, Honeybee. Honeybee allows the evaluation of indoor daylighting by connecting the Grasshopper visual programming environment with the validated light simulation engines for ray tracing Radiance and Daysim (Acosta et al., 2015; Reinhart \& Breton, 2009; Reinhart \& Walkenhorst, 2001). For such evaluation, the sensors were set up in a grid on the first floor of the building to be analyzed; the analysis area is reduced only to the six-meter depth concerning facade, being the greatest depth that daylight can reach inside a building the "active zone". A sensitivity analysis is also performed for different values of the Radiance daylight calculation parameters to balance the optimization of the calculation time and the accuracy of the light calculation.

This evaluation was carried out on the lower floor of the building as it is the most unfavourable floor in terms of the illuminance evaluation of the sDA metric.

\subsection{Multi-criteria Analysis and Optimization}

The results obtained from the performance indicators have been exported to a spreadsheet application for the processing and multicriteria analysis of the output data, 
through the Colibri plugin of Grasshopper, as well as to the software Design Explorer for their visualization.

To achieve a set of environmental design criteria, optimization was carried out using Grasshopper's Octopus component. Octopus allows programming evolutionary algorithms based on predefined parameters to optimize multiple object functions; as well as defining the optimal design parameter values to improve environmental performance. The use of this component is crucial to relate the parameters and performance indicators (indoor light accessibility and outdoor microclimatic conditions).

The results obtained from the multicriteria optimization have been exported, finally, once again for the processing and analysis of the output data.

\section{METHODOLOGICAL APPLICATION IN A CASE STUDY}

The application of the proposed methodology has been carried out using a small sample of the study. This case of study is located in the city of Seville (Spain), with a latitude of $37.42^{\circ}$ and a longitude of $5.40^{\circ}$. Seville has a Mediterranean climate, with mainly clear skies and warm and dry summers. In addition, these high heat periods are prolonged, extending from May to September, raising the level of discomfort and also acting as a risk factor for the health of the inhabitants. Furthermore, Seville has a significant percentage of its contemporary buildings without a suitable adaptation to the local climate conditions. For the analysis, a typical urban expansion configuration has been chosen (Figure 5), since it can be considered as the most frequent urban configuration in newly constructed neighbourhoods.

\subsection{Input Parameters}

As mentioned above, the weather conditions correspond to the city of Seville, and they are imported to Grasshopper as EnergyPlus weather files (*.epw) by Ladybug. In this case, the static building and urban input parameters used are those shown in Table 2. For its part, default daylighting radiance settings have been entered as shown in Table 3.

As dynamic parameters, to assess the proper use of daylight and improve microclimatic conditions, two orientations have been considered in the urban analysis, N-S/E-W (0.0) and NE-SW/NW-SE (45.0) orientations, in each iteration. In addition, regarding the urban canyon, different street widths $(5,10,15,20$, $25,30,35$, and $40 \mathrm{~m}$ ) were considered, generating different urban canyon proportions.

\subsection{Case Study Results}

The results show a direct relationship between urban canyon ratio and daylight accessibility; the lower H/W ratio, the higher the sDA metric. For its part, orientation does not significantly affect solar accessibility, according to this location (Figures 6 and 7).
Likewise, the proportion of urban canyon $\mathrm{H} / \mathrm{W}$ equal to or greater than one had practically no effect on MRT; however, for lower ratios, MRT increases (Figure 7). Orientation also did not have a significant effect on the average MRT outdoors. However, if the detailed behaviour of each orientation is analyzed, a significant temperature difference between each orientation in $\mathrm{N}$ $\mathrm{S} / \mathrm{E}-\mathrm{W}$ urban distribution is observed. Nevertheless, in NE-SW/NW-SE urban distribution, similar temperature values on all facades of the block are achieved.

\subsection{Analysis of results}

From the results of this limited-size case study, it can be concluded that a lower proportion of urban canyons in the urban fabric will significantly improve the solar accessibility of buildings in urban configurations, without significantly varying the outside MRT if this proportion is equal to or higher than $4 / 5$ ratio.

Furthermore, for proportions equal to or lower than a ratio of 4/5, the NE-SW / NW-SE orientation appears to obtain more favourable values, as it shows a more uniform thermal behaviour on all the building facades. Such lower ratios, in turn, favour street ventilation and reduce UHI in the urban canyon. Furthermore, ratios equal to or greater than do not allow sufficient solar access, leading to increased energy demand and, therefore, to lower buildings energy savings.

Therefore, an inappropriate ratio can affect not only the economy of the occupants but also their health and visual comfort. However, thermal variations in proportions greater than $4 / 5$ are imperceptible. It is necessary to reduce this ratio below $4 / 5$ so that outdoor MRT begins to increase significantly.

Table 2. Static simulation parameters.

\begin{tabular}{lc}
\hline Static Input Parameters & Values \\
\hline Window-to-Wall Ratio (WWR) & $25 \%$ \\
\hline Glazing transmittance & 0.55 \\
\hline Interior building reflectance & 0.50 \\
\hline Building typologies & Courtyard \\
\hline Building use & Residential \\
\hline Average urban height & $20 \mathrm{~m}$ \\
\hline $\begin{array}{l}\text { Maximum sensible } \\
\text { anthropogenic heat flux of the } \\
\text { urban area }\end{array}$ & $20 \mathrm{~W} / \mathrm{m} 2$ \\
\hline $\begin{array}{l}\text { Context reflectance } \\
\text { Trees and grass cover }\end{array}$ & 0.35 \\
\hline
\end{tabular}

Table 3. Daylighting Radiance Settings.

\begin{tabular}{lc}
\hline $\begin{array}{l}\text { Static Input } \\
\text { Parameters }\end{array}$ & Values \\
\hline Ambient bounces & 2 \\
\hline Ambient division & 5000 \\
\hline Limit Weight & $2 \mathrm{e}-5$ \\
\hline
\end{tabular}




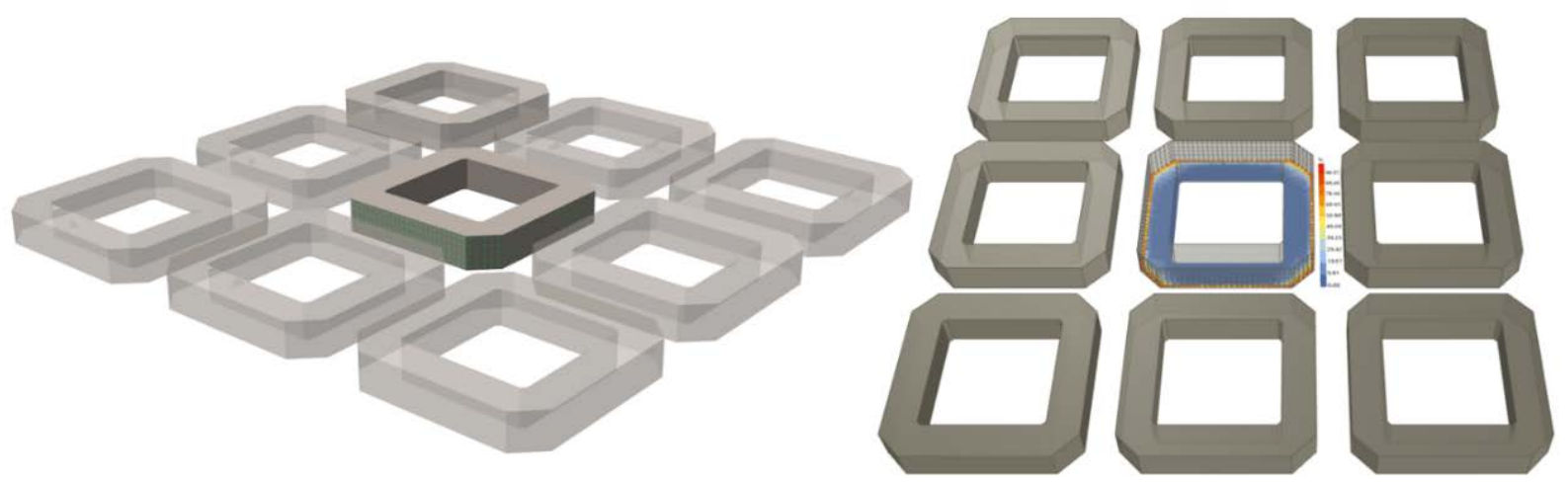

Figure 5. Urban geometry and Daylight Autonomy map for the lower floor of the building (Case Study).

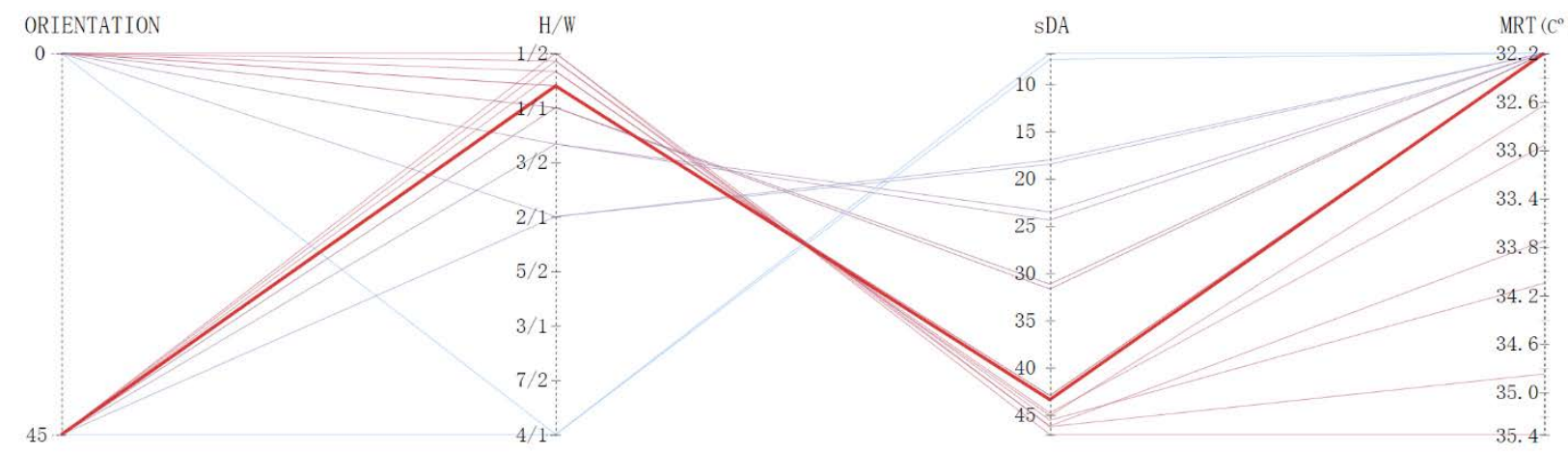

Figure 6. Results for the case study iterations.

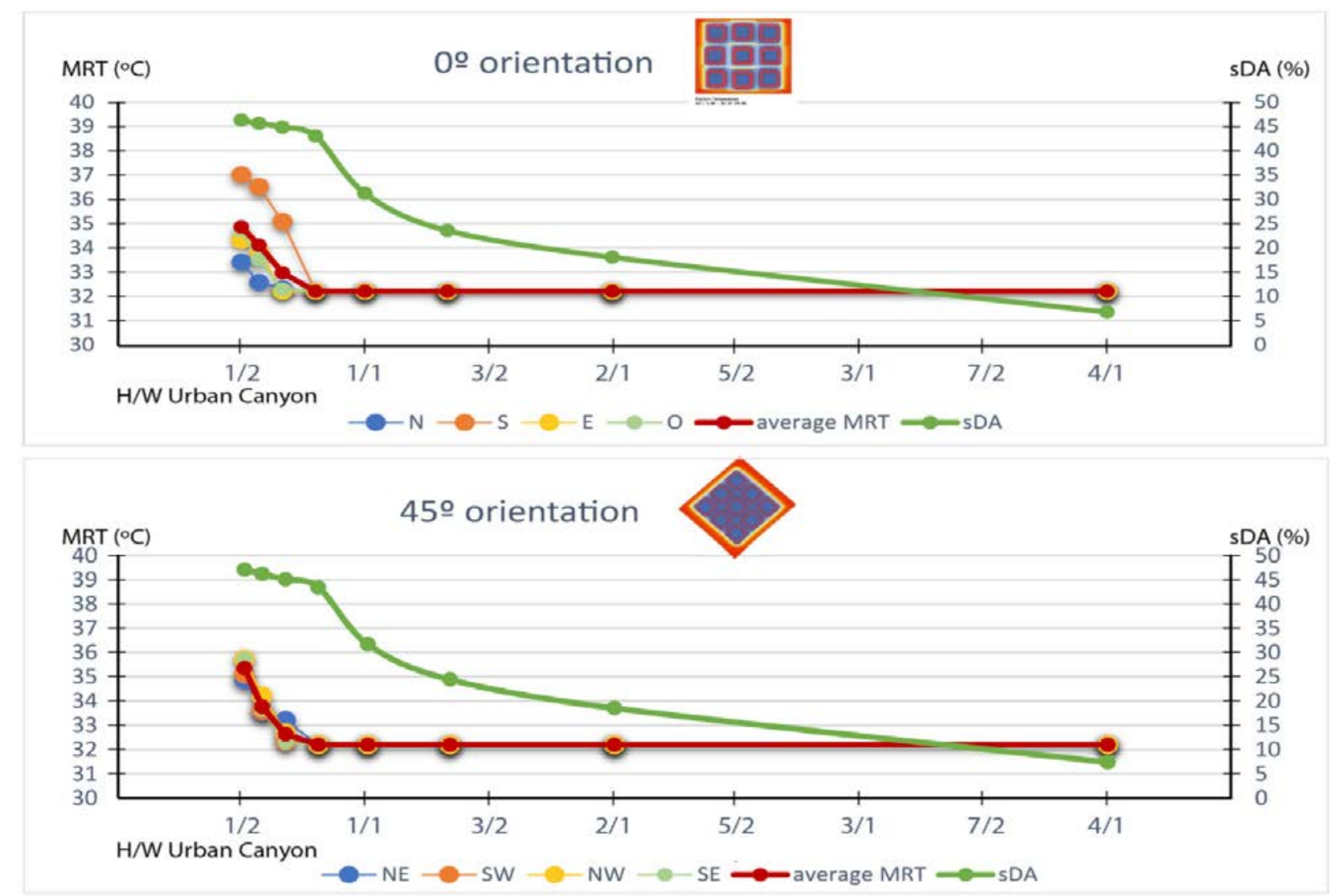

Figure 7. Urban canyon proportion and spatial Daylight Autonomy correlation. 
Thus, the 4/5 urban canyon ratio allows obtaining adequate indoor solar access while the outdoor thermal radiation is also controlled. In addition, for this proportion, orientation is not a significant parameter.

Finally, it should be noted that, when the urban canyon ratio is equal to or lower than $4 / 5$, this ratio becomes a more important parameter than orientation for the daylight access and outdoor temperature optimization process. However, orientation begins to be more relevant when the H/W ratio is lower than 4/5. Thus, it must be taken into account that, with lower $\mathrm{H} / \mathrm{W}$ ratios, the $\mathrm{N}-\mathrm{S}$ orientation can cause a thermal imbalance in the different facades of the building, with the spaces located on the south facade suffering higher temperatures. In these cases, the use of vegetation on the street (depending on the type of vegetation, size, and density, as well deciduous or evergreen) can be another possible strategy to reduce overheating and direct solar radiation on buildings.

It should be noted that these conclusions are only valid for the hypotheses under study, which are based on a specific case of a typical urban configuration located in the city of Seville. In addition, these hypotheses have the initial limitation, or premise, of having all the urban blocks the same, with the same shape, height, orientation and distance between them.

In addition, this case study requires a more in-depth analysis introducing other urban parameters, as the reflectance of the materials, shadow cast by vegetation, window-to-wall ratio, buildings coverage ratio and urban density.

This is because this case study has been used to show the efficacy and functionality of the methodological proposal presented in this paper.

\section{DISCUSSION}

Nowadays, the promotion of energy savings and wellness in buildings is common, and the urban scale plays a fundamental role in achieving it. Nevertheless, a larger-scale analysis involves a much more complex calculation.

Therefore, the purpose of this research was to propose an experimental methodology capable of performing a multi-objective analysis while reducing computational costs.

Thus, this study presents an experimental methodological proposal based on a parametric workflow through Grasshopper and Ladybug Tools.

This experimental method allows the integration of urban data sets with the different tools used in a parametric and dynamic workflow, allowing multicriteria consideration, for better design options.

The novelty of this research also lies in:

- The use of sDA daylight metric to indicate the daylight sufficiency of the spaces.

- The multi-objective analysis of contradictory or conflicting aspects (indoor daylight access and outdoor thermal comfort).
- The integration of UWG in the workflow, taking into account the climate effect produced by the urban environment (UHI).

- The use of Grasshopper's Octopus component, which allows programming evolutionary algorithms to optimize multiple object functions. Its use is crucial to relate both urban parameters and performance indicators.

In this way, this new methodological approach can contribute to performing more complex analyses (at the urban scale, with the possibility of introducing numerous parameters and variables) to achieve more solid studies. This is done in a faster and easier way due to the multi-objective optimization and the coupling of several simulation engines in a single workflow.

The results obtained in the case study presented in this paper prove the method viability of such workflow. For this reason, the importance of this document is based not on the case study results, but the new methodological proposal potential.

Finally, it is worth highlighting the workflow power to find differences and similarities between the optimal values of design parameters in different urban configurations and climates; as well as to establish, locally or globally, design guidelines as support tools in urban design.

\section{CONCLUSION}

This research presents a methodological proposal based on a parametric workflow through Grasshopper and Ladybug Tools. Its purpose is to define the optimal values of urban parameters to improve both daylight access and outdoor thermal comfort.

The results obtained in the case study presented in this paper prove the method viability of such a workflow to determine a set of environmental design criteria at an urban scale from a multi-criteria analysis. This can be further validated with real-world on-site tests.

From the results of the case study, located in Seville (Spain), the 4/5 ratio of the urban canyon seems to be the optimal $\mathrm{H} / \mathrm{W}$ proportion analyzed to achieve the greater thermal and daylight comfort values for the typical urban expansion configurations. On the other hand, placing buildings with a NE-SW/NW-SE orientation with urban canyon ratios equal or lower to 4/5 shows a better average thermal performance in all the facades.

The novelty of this research is based on the analysis of the proper use of daylight, simultaneously considering the two aspects in an integrated way. On the one hand, the effect of the urban environment on solar access by using sDA dynamic lighting metric in an urban context; on the other, the analysis of the modification of the urban morphology on outdoor thermal radiation and UHI phenomenon.

As a limitation of the research, it is necessary to have a deeper analysis introducing other urban 
parameters such as material reflectance, the shadow cast by vegetation, window-to-wall ratio, building coverage ratio, or urban density. In addition, the integration of other performance indicators, such as other dynamic daylight metrics (ASE,cDA, DAm, ...), the dynamic outdoor thermal comfort metric OTCA (that assess the links between the outdoor environment and human well-being), operational energy should be implemented. Finally, the proposed methodology should be tested in other climate locations and urban configurations.

\section{CONFLICT OF INTEREST}

The authors declare no conflict of interest.

\section{FUNDING}

The results presented were funded by the Agencia Estatal de Investigación (AEI) and the Ministerio de Ciencia e Innovación (MCIN) of the Government of Spain through the research project DYNALIGHT: Efficient design for biodynamic lighting to promote the circadian rhythm in shift work centres (Ref BIA201786997-R). The authors wish to express their thanks for all the technical and financial support provided.

\section{ACKNOWLEDGMENT}

The authors thank the Estatal de Investigación (AEI) and the Ministerio de Ciencia e Innovación (MCIN) of the Government of Spain. The authors are also grateful to all developers of the open-source engine: Ladybug Tools, Colibri, Octopus, including the teams of EnergyPlus, OpenStudio, Radiance and Urban Weather Generator.

\section{REFERENCES}

Acosta, I., Campano, M. Á., \& Molina, J. F. (2016), Window design in architecture: Analysis of energy savings for lighting and visual comfort in residential spaces. Applied Energy, 168, 493-506.

Acosta, I., Munoz, C., Esquivias, P., Moreno, D., \& Navarro, J. (2015), Analysis of the accuracy of the sky component calculation in daylighting simulation programs. Solar Energy, 119, 54-67.

Alexander, P. J., Mills, G., \& Fealy, R. (2015), Using LCZ data to run an urban energy balance model. Urban Climate, 13, 14-37.

Ali-Toudert, F., \& Mayer, H. (2006), Numerical study on the effects of aspect ratio and orientation of an urban street canyon on outdoor thermal comfort in hot and dry climate. Building and Environment, 41(2), 94-108.

Bellia, L., Acosta, I., Campano, M. Á., \& Fragliasso, F. (2020), Impact of daylight saving time on lighting energy consumption and on the biological clock for occupants in office buildings. Solar
Energy, 211(September), 1347-1364.

Bueno, B., Nakano, A., \& Norford, L. (2015), "Urban weather generator: A method to predict neighborhood-specific urban temperatures for use in building energy simulations” in ICUC9 - 9th International Conference on Urban Climate Jointly with 12th Symposium on the Urban Environment, $i$.

Committee, I. E. S. D. M. (2012), IES Spatial Daylight Autonomy (sDA) and Annual Sunlight Exposure (ASE), Daylight Metrics Committee. Approved Method IES LM-83-12. Illuminating Engineering Society of North America.

Compagnon, R. (2004), Solar and daylight availability in the urban fabric. Energy and Buildings, 36(4), 321-328.

Fundamentals, A. H. (2001). SI Edition, Atlanta: American Society of Heating. Refrigeration and Air-Conditioning Engineers, Inc.

Givoni, B. (1989), Urban Design in Different Climates.

l'Eclairage, C. I. de. (2003), Spatial Distribution of Daylight-CIE Standard General Sky. ISO, 15469.

Lowry, W. P. (1977), Empirical estimation of urban effects on climate: a problem analysis. Journal of Applied Meteorology, 16, 129-135.

Naboni, E., Natanian, J., Brizzi, G., Florio, P., Chokhachian, A., Galanos, T., \& Rastogi, P. (2019), A digital workflow to quantify regenerative urban design in the context of a changing climate. Renewable and Sustainable Energy Reviews, 113(June), 109255.

Nakano, A., Bueno, B., Norford, L., \& Reinhart, C. F. (2015), "Urban Weather Generator - A novel workflow for integrating Urban Heat Island effect within urban design process”. Building Simulation Conference, 1901-1908.

Natanian, J., \& Auer, T. (2020), Beyond nearly zero energy urban design: A holistic microclimatic energy and environmental quality evaluation workflow. Sustainable Cities and Society, 56(February), 102094.

Núñez Peiró, M., Sánchez-Guevara Sánchez, C., \& Neila González, F. J. (2017), Update of the urban heat Island of madrid and its influence on the building's energy simulation. In Sustainable Development and Renovation in Architecture, Urbanism and Engineering (pp. 339-350). Springer International Publishing.

Observatori Metropolità del Canvi Climàtic. (2015), La isla de calor en el área metropolitana de Barcelona y la adaptación al cambio climático. 101.

Oke, T. R. (1988), Street design and urban canopy layer climate. Energy Build, 11,

Perez, R., Seals, R., Michalsky, J., \& Sciences, A. (1993), All-weather model for sky luminance distribution--preliminary configuration and validation. 50, 235-245.

Ratti, C., Baker, N., \& Steemers, K. (2005), Energy 
consumption and urban texture. Energy and Buildings, 37(7), 762-776.

Reinhart, C. F., \& Breton, P.-F. (2009), Experimental Validation of Autodesk ${ }^{\circledR}$ 3ds Max ${ }^{\circledR}$ Design 2009 and Daysim 3.0. LEUKOS - Journal of Illuminating Engineering Society of North America, 6(1), 7-35.

Reinhart, C. F., \& Walkenhorst, O. (2001), Validation of dynamic RADIANCE-based daylight simulations for a test office with external blinds. Energy and Buildings, 33(7), 683-697.

Roudsari, M. S., \& Pak, M. (2013), “Ladybug: A parametric environmental plugin for grasshopper to help designers create an environmentallyconscious design”. Proceedings of BS 2013: 13th Conference of the International Building Performance Simulation Association, 3128-3135.

Salvati, A., Coch Roura, H., \& Cecere, C. (2016), Urban Heat Island prediction in the Mediterranean context: An evaluation as the Urban Weather Generator model. Architecture, City and Environment, 11(32), 135-156.

Salvati, A., Monti, P., Coch Roura, H., \& Cecere, C.
(2019), Climatic performance of urban textures: Analysis tools for a Mediterranean urban context. Energy and Buildings, 185, 162-179.

Street, M., Reinhart, C., Norford, L., \& Ochsendorf, J. (2013), "Urban heat island in boston - An evaluation of urban airtemperature models for predicting building energy use”. Proceedings of BS 2013: 13th Conference of the International Building Performance Simulation Association, 1022-1029.

Taleb, H., \& Musleh, M. A. (2015), Applying urban parametric design optimisation processes to a hot climate: Case study of the UAE. Sustainable Cities and Society, 14(1), 236-253.

Wong, I. L. (2017), A review of daylighting design and implementation in buildings. Renewable and Sustainable Energy Reviews, 74(July 2016), 959968.

Xue, P., Mak, C. M., \& Cheung, H. D. (2014), The effects of daylighting and human behavior on luminous comfort in residential buildings: A questionnaire survey. Building and Environment, 81, 51-59. 